\title{
Is Beekeeping Affected by the Use of Neonicotinoids in Agriculture?
}

\author{
Erzsébet-Timea DOMOKOS ${ }^{1}$, Liviu Alexandru MARGHITAS ${ }^{1}$, Daniel Severus DEZMIREAN ${ }^{1}$ and Otilia \\ BOBIS $^{2 *}$
}

\author{
${ }^{1}$ Department of Apiculture and Sericiculture. University of Agricultural Sciences and Veterinary \\ Medicine Cluj-Napoca, Romania. \\ ${ }^{2}$ Life Science Institute "King Michael I of Romania", University of Agricultural Sciences and Veterinary \\ Medicine Cluj-Napoca, Romania. \\ *Corresponding author, e-mail: obobis@usamvcluj.ro
}

Bulletin UASVM Animal Science and Biotechnologies 74(2)/ 2017

Print ISSN 1843-5262; Electronic ISSN 1843-536X

DOI:10.15835/buasvmcn-asb: 0021

\begin{abstract}
Neonicotinoids are systemic insecticides used in agriculture for seed treatment as well as in the pest control by spraying during plant growing. Also, they are found as an active substance in different phytosanitary products used in horticulture for winter spraying in fruit plantations when fruit trees are in vegetative rest. Taking into account the former studies on this topic, knowing all what is published regarding this important theme, both for agriculture and for beekeeping, the review is very important for all interested parts. In the present review many of the questions raised by the beekeepers and the scientists from agriculture receive an answer, together with described methods for identifying and quantifying this class of still used pesticide.
\end{abstract}

Keywords: agriculture, beekeeping, chemical determinations, neonicotinoids

\section{INTRODUCTION}

Beekeeping is an important sector of animal husbandry that studies the biology and technology of bees in order to obtain high amounts of bee products and increase seed production in entomogene plants as a result of pollination (Gleiciani et al., 2014).

In our country, thanks to favorable pedoclimatic conditions and rich honey bases, apiculture has an old tradition (Iancu, 2012). Pretty mild winters, sunny days, warm summers, as well as warm, serene days are good for beekeeping. Revitalizing this sector will only be possible by applying the beekeeping law in force and only with the help of professional beekeepers able to diversify apiculture production and willing to adapt to the market economy.

Honey has been found to be one of the most complex products from a biological point of view (Viuda-Martos et al., 2008), a very good carbohydrate source that is easily digestible, natural and provides quick energy.

In addition to its pleasant taste and nutritional composition, honey also has a number of properties, low humidity is an important part of the system that protects honey from the attack of microorganisms. The hyperosmotic nature of honey (due to its high carbohydrate content and low water content) inhibits the growth and development of bacteria and yeasts by dehydration and killing (Kevan et al., 2007). High acidity of honey also plays an important role in the bacterial growth prevention system. Honey $\mathrm{pH}$ may range from 3.2 to 4.5 (with an average of 3.9) being unsuitable for the attack of most bacteria (White, 1957).

By definition, honey is a wholly natural product that contains neither additives nor preservatives. According to European legislation, the simple word "honey” on the packaging is sufficient to 
<smiles>O=[N+]([O-])/N=C1\NCCN1Cc1ccc(Cl)nc1</smiles><smiles>CN1COCN(Cc2cnc(Cl)s2)/C1=N/[N+](=O)[O-]</smiles>

Thiamethoxam<smiles>N#CN=C1SCCN1Cc1ccc(Cl)nc1</smiles>

Thiacloprid

Fig. 1. Chemical formula of most used neonicotinoids

ensure the consumer that is $100 \%$ natural and clean (Bogdanov, 2006).

Neonicotinoids are a class of sistemic insecticides including imidacloprid, thiamethoxam and thiacloprid (Figure 1), with a chlorosubstituted heterocyclic group, used in seed treatment, and in the curative control of pests by spraying during vegetation period of plants and crops.

They are used since 1990 to control different pests, nowadays being abolut $30 \%$ from the global insecticide production (Jeschke et al., 2011). Also neonicotinoids are found as active substance in differentfitosanitary products, used in horticulture for winter spraying in orchards, when trees are in vegetative rest. These products although contain neonicotinoids, were not banned. The use of neonicotinoids was prohibited for seed treatment, for spraying in vegetation period, but is allowed to be used in vegetative rest spraying of fruit trees and ornamental trees.

Sistemic means that the active substance from the insecticid is absorbed by the plant in cellular juice, and from there it reaches the pest organism by ingestion. Practically, they consume the treated plants and die by poisoning (Goulson, 2013). Neonicotinoids are neurotoxic compounds acting upon the nervous system of the pests (Aliouane et al., 2009).

The name „neonicotinoids" is derived from the way of action upon insects which ingered these products. Immediately after ingestgion, the pest falls off the plant, its body being paralyzed by the active substance from the product, which act upon the nervous system.

Cultures crops in our country are being attacked by a bunch of very dangerous pests, which within a few days can destroy a whole culture. For example, the biggest problem, especially for farmers in southern Romania, is the corncrake (Tanymecus dilaticollis). This pest can destroy hundreds of hectares of corn in a very short time. Unfortunately for us, the pest is mainly located in our country, weaker in the neighboring countries, in the Western countries is not a problem, and hence the higher interest of Romanian farmers towards these insecticides. Also, precisely because Romanian farmers seem to be the most affected by this situation, it immediately led to the formulation of a true theory of conspiracy.

An enormous advantage of neonicotinoids is that they act very targeted. It practically kills the problematic pests, not affecting the other insects, and also the risk of having a negative impact on human health is low.

Neonicotinoids have already a history of more than 20 years, but EU forbids the use of these products in the treatment of seeds, as well as for spraying the plants in vegetative period (Table 1).

Products containing neonicotinoids can be used only to spray fruit trees during vegetative rest periods (Tomizawa et al., 2005). They have a good activity against different families of sucking insects such as Heteroptera, Coleoptera, Lepidoptera, but 
Tab. 1. Main nedonicotinoid insecticides (source: Fairbrother et al., 2014; Environmental Toxicology and Chemistry, vol.33, no.4, 719-731)

\begin{tabular}{|c|c|c|}
\hline $\begin{array}{c}\text { Name of } \\
\text { neonicotinoid }\end{array}$ & $\begin{array}{l}\text { Year of } \\
\text { registration }\end{array}$ & Uses \\
\hline Acetamiprid & 2002 & $\begin{array}{l}\text { Leafy and fruiting vegetables, cole crops, citrus, cotton, pome fruits, } \\
\text { ornamentals. Effective against ants, beetles, boxelder bugs, centipedes, } \\
\text { chiggers, cockroaches, crickets, earwigs, firebrats, fleas, gnats, flies, } \\
\text { millipedes, mosquitoes, moths, pillbugs, scorpions, silverfish, spidermites, } \\
\text { spiders, stink bugs, ticks, termiktes, wasps }\end{array}$ \\
\hline Clothinidin & 2003 & $\begin{array}{l}\text { Corn, canola, grapes, pome fruit, rice, tobacco, turf, ornamentals. Effective } \\
\text { against a wide variety of turf and sucking insects, including flies, beetles, } \\
\text { moths, true bugs }\end{array}$ \\
\hline Dinotefuran & 2012 & $\begin{array}{l}\text { Cotton, mustard, tgurf, lawn-and-garden use, vegetable crops, residentiazl } \\
\text { indoors. Effective on a broad specgtrum of insects, including aphids, } \\
\text { whiteflies, thrips, leafhopper, leafminer, sawfly, mole cricket, whited grubs, } \\
\text { lacedbugs, billbugs, beetles, mealubugs, sawfly larvae, cockroaches } \\
\end{array}$ \\
\hline Imidacloprid & 1992 & $\begin{array}{l}\text { Cotton, rice, cereals, peanuts, potatoes, vegetables, pome fruits, pecans, } \\
\text { turf. Sffective against sucking and soil insects, whiteflies, termites, turf } \\
\text { insects, Colorado potato beetle }\end{array}$ \\
\hline Nitenpyram & 2006 & Veterinary product for use on cats and dogs for flea control \\
\hline Nithiazine & 2011 & $\begin{array}{l}\text { House fly control in animal facilities (poultry, feedlots, dairy, sgtab les) and } \\
\text { industrial locations }\end{array}$ \\
\hline Thiacloprid & 2003 & $\begin{array}{l}\text { Cotton and pome fruits. Effective against a variety of sucking insects, } \\
\text { including aphids and whiteflies, codling moth, plum curculio }\end{array}$ \\
\hline
\end{tabular}

also insects that have resistance to carbamates, chlorinated hydrocarbons, organophosphorus insecticides or pyrethroids (Nauen et al.. 2003), but and are less toxic to birds and mammals. But research studies says that the extensive use of neonicotinoids, in periods that are forbidden to be used may be correlated to a decline of pollinating species, especially Apis mellifera L., when visiting melliferou plants (Halm et al., 2006; SamsonRobert et al., 2014; Williams et al., 2015).

The honey bee's mortality or decline is due to multi-factorial motives, which involve the presence of parasites and different pathogens, but not least the pesticide stressors (Sanchez-Bayo et al., 2016). Bees are veryh sensitive to climate changes, to the presence of different contaminators in air of upon plants from where they collect nectar and pollen. Are considered the best living environmental indicators (Naccari et al., 2014).

The present study was carried out due to the fact that we consider of great importance the action of these classes of insecticides upon bees' life and honey production.

\section{BEE DECLINE AND INSECTICID USE}

With regard to seed treatment using different insecticides, bee decline caused by the presence of neonicotinoids can be produced as follows: seeds can be treated with an inadequate amount of insecticide and when they are seeded, by rubbing of one another, to the wrapping and sowing machine, the substance may detach from the seeds, and then may be carried by the wind, get in contact with the bees, the meliferous plants, and hives.

This type of contamination was clearly proved, many bee families were affected by this mistake of farmers (Iwasa et al., 2004).

The second type of contamination may occur when the active ingredient of the insecticide the seed was treated by, penetrates through the radon into the plant's juice and then at the flowering part, it reaches up to the floral organs, including pollen and nectar in small amounts.

Concerning this type of contamination, there are many questions to ask. No study done so far has come up with a clear answer that would bring with no doubt the proof that neonicotinoid seed 
treatment affects the bees. Also, a very important aspect of seed treatment is the fact that only a small part of the insecticide penetrates the plant, most of it remains in the soil and there is the fear that this insecticide might accumulate in the soil with devastating effects on the useful micro-fauna.

The third type of contamination would be the neonicotinoid treatment in the vegetation phase. This type of treatment may be the most damaging for beekeepers. Although these insecticides are not approved for use during flowering, there still are farmers who fail to take this into account and treat the fruit trees even when they are blooming. Therefore, the substance reaches directly on the flowers and from there in the nectar and pollen, and the bees are safe victims.

This type of practice is the worst for bees, but gladly also the easiest to prove with laboratory tests.

In the US, Canada, and more recently in Europe, an impressive number of bee families die every year, the result of the "coroners" being the collapse of bee families. In the US, this syndrome takes massive depopulation every year, and important research is currently underway to identify the cause of this and also the solutions (Kevan et al., 2007).

This syndrome was known long before the neonicotinoids appeared on the market and were used in agriculture, due to increasingly aggressive diseases and more and more pests in front of which the bees can not cope. However, even now, all details of this syndrome are unknown.

In connection with neonicotinoids, these insecticides are believed to have reached infinite amounts in the nectar of the flowers, then in the beeswax cause the bees' immunity to decrease. Although laboratory analyzes do not find the active substance in the insecticide as a cause of death, it is still thought that the insecticide may cause the parasite or disease to break down the host. Practically, the insecticide is "soap on the rope".

But unfortunately research studies is knocking head on, not responding clearly to the subject. What is $100 \%$ clear is that neonicotinoids caused bee death when the dust with the active substance from the seed, carried by the wind, reached bees or honey plants.

Different studies documented the acute toxicity of neonicotinoids in honeybees after oral and topical and subchronic exposure (El Hassani et al., 2008; Aliouane et al., 2009). Particularly, the sub-lethal doses of neonicotinoids modify honey bee behaviours, larval development, reproduction activity and longevity (Di Prisco et al., 2013; Fairbrother et al., 2014), and inhibit bees' immune defence, bees becoming more susceptible to infection (Abbo et al., 2016).

After certain scientific studies were published, the European Union has restricted the use of certain neonicotinoids, such as imidacloprid and clothianidin, confirming a high acute risk to honey bees exposed via dust drift for the seed treatment uses incereals, oilseed rape and maize, and also via residues in nectar and/or pollen (EFSA 2015).

\section{METHODS TO DETECT THE PESTICIDE IN BEES AND BEE PRODUCTS}

Gas chromatography (GC) and mass spectrometry (MS) in tandem, make an efficient chemical analysis of pesticides. The use of GC-MS system is optimal when:

- It is desirable to identify or characterize analyts

by providing concrete results, from this point of view being a tool of conclusive proof of identity; -It is desirable to increase the analytic sensibility

High Performance Liquid Chromatography coupled with (HPLC) mass spectrometry (MS) is also used for the identification and quantification of different neonicotinoid classes.

\section{Gas-chromatography}

GC analysis is a common confirmation test discovered by Mikhail Semenovich Tsvett.. A gas chromatograph consists of an injection port, a column, carrier gas control equipment, temperature-controlled furnaces and heaters, a graphical recorder and a detector (Figure 2).

To separate the compounds, a sample solution containing the organic compounds of interest is injected through the port of the mantle where it is to be vaporized. The vaporized sample is then transported by an inert gas, the most commonly used being helium and hydrogen. In GC analysis some chemical and physical characteristics of the molecules make them migrate through columns at different speeds (Vincent et al., 1992). If the molecule has low molecular weight, it will migrate faster. At the same time, the time of exit from the column is also affected by the shape of the molecule. Interactions between the molecules and the surface of the column make the molecule 
of compounds

Ions separated

according to the mass

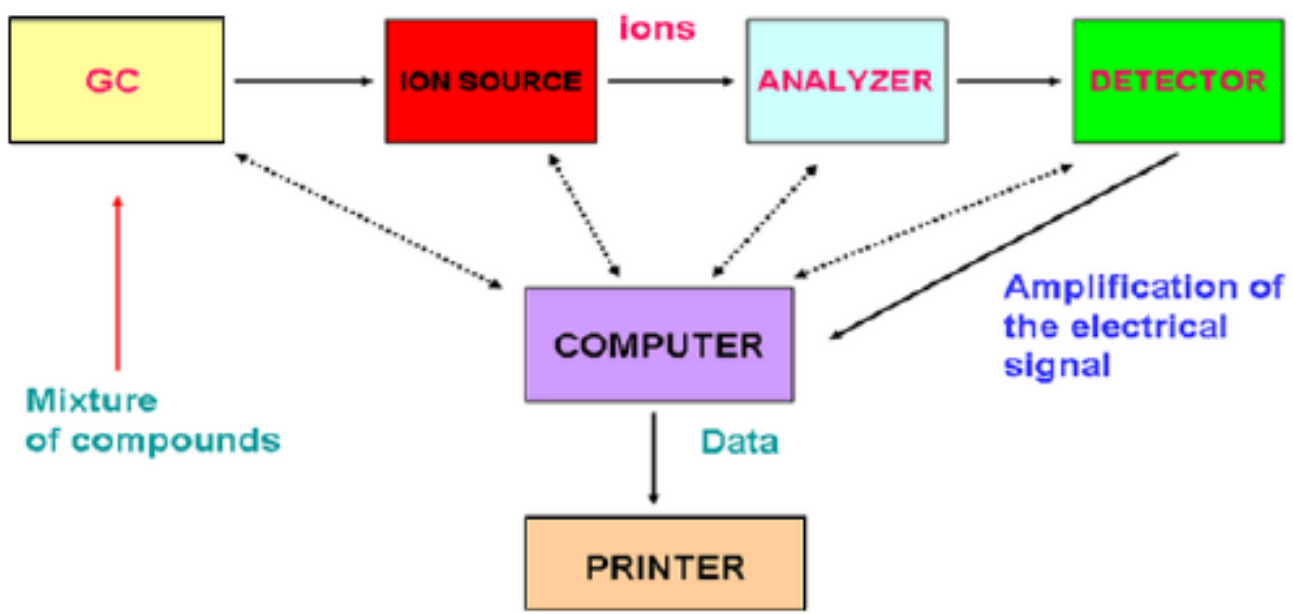

Fig. 2. Block diagram of GC-MS (https://www.researchgate.net/figure/280931991)

retained inside the column in a different time from the other molecules present in the mixture.

\section{Mass spectrometry}

Mass spectrometry allows the measurement of relative molecular masses of some compounds as well as highlighting the functional groups present in the analyzed compound. To measure the individual characteristics of the molecules, a mass spectrometer converts them into ions to be transported and manipulated by electromagnetic fields. The graphical representation (chromatogram) displays the mass of each fragment. The table sprays can also be used for qualitative identification. All mass fragments are then used as puzzle pieces to identify the mass of the original molecule, thus revealing the identity of the specimen in the sample.

High Performance Liquid Chromatography

High Performance Liquid Chromatography (HPLC) covers today, approximately $80 \%$ of the analysis of organic, organometallic and inorganic molecular substances, including highly polar and thermally labile compounds as well as high molecular weight compounds (natural or synthetic). That is why, together with gas chromatography, it is an important support point in modern chemical analyzes. Although the column efficiency is not yet equal to that of the GC, by the fact that it is possible to modify the mobile phase, besides the stationary phase, liquid chromatography (LC) makes possible separations and analyzes sometimes impossible to achieve by other techniques. Coupling with mass spectrometry has lately transformed this method into the primary means of analyzing natural or synthetic molecular compounds, constituting one of the pillars on which current synthetic chemistry is based and on which modern biochemistry and biotechnology have developed.

HPLC uses a steel column loaded with different materials (stationary phase), a pump, two or three that pushes the mobile phase (s) through the column and a detector showing the retention times of the molecules. Retention time depends on the interaction between the stationary phase, the molecules to be analyzed and the solvents used.

The sample to be analyzed is introduced in small volume into the mobile phase stream. The passage of the analyte through the column is slowed down by the presence of chemical or physical interactions in the stationary phase, these passing along the column. Total slowdowns depend on each analyte, stationary phase and mobile phase composition. The time at which a specific analyte elutes (goes out of the column) is called retention time; Retention time under particular conditions is considered a unique characteristic of identifying the given analyte. Using a small particle loaded column (which creates a higher pushing pressure) increases the linear velocity, giving the compounds the minimum time to diffuse through the column, thus leading to an improvement in the resulting chromatogram resolution. Common solvents which are used in the separation, include any 
miscible combination of water or various organic liquids (typically methanol or acetonitrile). The water may contain buffers or salts which help to separate the analyte components or components as trifluoroacetic acid which act as an ionic mating agent.

It has been estimated that the sample preparation phase consumes, in most determinations, approximately $60-70 \%$ of the total time required for the assay. In routine analyzes, this phase must be able to produce accurate analytical results, be economically efficient, safe and easy to achieve and applicable to a wide variety of pesticides: organochlorine, organophosphorus, pyrethroids, neonicotinoids etc.

Methods of sample preparation for the determination of gas chromatographic (GC) and liquid chromatographic methods (LC) include the following steps:

1. Homogenization of sample to obtain a uniform matrix;

2. Solvent extraction of pesticide residues;

3. Purification step to eliminate the interference of the matrix components;

4. Elution and/or fractionation of extracted analytes;

5. Concentration of the extract and reconstitute it in a solvent that is compatible with GC or LC conditions;

6. Analyzing the extract via GC or LC.

The first step in the sample preparation process is to obtain a homogeneous sample and a homogeneous mixture. Numerous studies demonstrate that the homogeneity of the sample and the quantity of the sample which will be analysed (10-25g) has an influence on the reproducibility of the results. Extraction with a homogenizer is the most commonly used method for separating nonionic pesticides from the matrix.

Although there are many methods of analysis and detection of pesticide residues, the extraction methods used are the same as in the first days of pesticide analysis, with some modifications and improvements.

Numerous organic solvents or solventmixtures are used to extract a wide range of pesticides with different physicochemical properties. Predominantly in the multi-residue analyzes the most used extraction solvents are acetonitrile, acetone and ethyl acetate, being used both at the beginning of the pesticide residue analyzes and in recent publications for the extraction of both nonpolar and polar pesticides of a great diversity of agricultural matrices.

\section{RESULTS OF DIFFERENT STUDIES ON NEONICOTINOID PRESENCE IN BEES AND BEE PRODUCTS}

A study of Cicero et al. (2016), determine the neonicotinoid concentrations in honeybees, honeycomb and honey samples collected in blooming period from different areas of Sicily, Italy. The overview of neinicotinoid contamination show that only one substance (Clothianidin), from the 5 standards used (Imidacloprid, Clothianidin, Thiamethoxam, Acetamiprid, Thiacloprid), was found in bee samples, but the concentrations found do not represent a risk for bee vitality and safety. In wax and honey samples, no neonicotinoids were quantified; this showing the quality of bee products was not affected.

The obtained data confirm the importance of monitoring on clothianidin, as specified by EFSA, for the greater risk to honey bees (EFSA 2015). The residues of clothianidin found, could be due to the use of neonicotinoids in agricultural practice.

The obtained data are in accordance with other studies (Krupke et al. 2012), on dead bees. But Kasiotis et al. (2014), found in bees samples more neonicotinoids (clothianidin, thiamethoxam and imidacloprid). These studies also show the absence of residue in all analyzed honey samples.

There are studies, instead, who found also in honey samples the presence of neonicotinoids, particularly Clothianidin, Thiamethoxam (Jones and Turnbull, 2016) and Imidacloprid (SanchezHernandez et al., 2016) in concentrations higher than detection limits.

Another interesting study (Tapparo et al., 2012) route the environmental exposure of honeybees to and intoxication with neonicotinoid insecticides from the atmospheric emission of particulate matter containing the insecticide by drilling machines. Using optimized analytical procedures, quantitative measurements of both the emitted particulate and the consequent direct

contamination of single bees approaching the drilling machine during the foraging activity have been determined. Experimental results show that the environmental release of particles containing neonicotinoids can produce high exposure levels 
for bees, with lethal effects compatible with colony losses phenomena observed by beekeepers.

\section{CONCLUSION}

The scientific studies confirm that honey bees living and foraging near agricultural fields could be exposed to pesticides as neonicotinoids. If all recommandation are respected when neonicotinoids are used in agriculture, a minor risk is presented, and not upon bee products, but mainly on bees. A regular monitoring is needed to evaluate the effects of these insecticides on bees behavior and their survival, considering that neonicotinoids and all pesticides in general, could be possible responsible for the decline of pollinating species, and honey production.

Aknowledgement: Financial support for $\mathrm{OB}$, D.S.D and L.A.M was granted by the project ADER $413 / 2015$, developed through the Ministery of Agriculture and Rural Development, Romania. The authors declare no conflict of interests.

\section{REFERENCES}

1. Abbo PM, Kawasaki JK, Hamilton M, Cook SC, DeGrandiHoffman G, Li WF, Liu J, Chen YP (2016). Effects of Imidacloprid and Varroa destructor on survival and health of European honey bees, Apis mellifera. Insect Sci. doi:10.1111/1744-7917.12335.

2. Aliouane Y, El Hassani AK, Gary V, Armengaud C, Lambin M, Gauthier M (2009). Subchronic exposure of honeybees to sublethal doses of pesticides: effects on behavior. Environ Toxicol Chem. 28:113-122.

3. Bogdanov S (2006). Contaminants of bee products, Apidologie, 37 (1), 1-18.

4. Cicero N, Naccari C, Cammilleri G, Giangrosso G, Cicero A, Gervasi T, Trfopea A, Albergamo A, Ferrantelli V (2016). Monitoring of neonicotinoid pesticides in beekeeping, Nat. Prod. Res., DOI: 10.1080/14786419.2016.1236101

5. Di Prisco G, Cavaliere V, Annoscia D, Varricchio P, Caprio E, Nazzi F, Gargiulo G, Pennacchio F. (2013). Neonicotinoid clothianidin adversely affects insect immunity and promotes replication of a viral pathogen in honey bees. Proc Natl Acad Sci USA. 110:18466-18471.

6. EFSA. 2015. Conclusion on the peer review of the pesticide risk assessment for bees for the active substance imidacloprid considering all uses other than seed treatments and granules. EFSA J.13:4211-4293.

7. El Hassani AK, Dacher M, Gary V, Lambin M, Gauthier M, Armengaud C (2008). Effects of sublethal doses of acetamiprid and thiamethoxam on the behavior of the honeybee (Apis mellifera). Arch Environ. Contam Toxicol. 54:653-661.
8. Fairbrother A, Purdy J, Anderson T, Fell R (2014). Risks of neonicotinoid insecticides to honeybees. Environ Toxicol Chem. 33:719-731.

9. Gleiciani B. Patrício-Roberto, Maria J. O. Campos (2014). Aspects of Landscape and Pollinators-What is Important to Bee Conservation?, Diversity, 6(1), 158-175.

10. Goulson D (2013). An overview of the environmental risks posed by neonicotinoid insecticides, J. Appl. Ecol., 50, 977-987.

11. Halm MP, Rortais A, Arnold G, Tasei JN, Rault S (2006). New risk assessment approach for systemic insecticides: the case of the honey bees and imidacloprid (Gaucho). Environ Sci Technol. 40:2448-2454.

12. https://www.researchgate.net/figure/280931991_fig2_ Fig-2-Block-diagram-of-a-GCMS

13. Iancu R, Oprean L, Codoi V (2012). Organic beekeeping and bee products, Scientific Papers. Series A. Agronomy, LV, 13-18.

14. Iwasa T, Motoyama N, Ambrose JT, Roe R M (2004). Mechanism for the differential toxicity of neonicotinoid insecticides in the honey bee, Apis mellifera, Crop Protect. 23, 371-378.

15. Jeschke P, Nauen R, Schindler M, Elbert A (2011). Overview of the status and global strategy for neonicotinoids. J. Agric. Food Chem. 59:2897-2908.

16. Jones A, Turnbull G (2016). Neonicotinoid concentrations in UK honey from 2013. Pest Manage Sci.72:1897-1900.

17. Kasiotis K, Anagnostopoulos C, Anastasiadou P, Machera $K$ (2014). Pesticide residues in honeybees, honey and bee pollen by LC-MS/MS screening: reported death incidents in honeybees. Sci Total Environ. 485:633-642.

18. Kevan PG, Eisikowitch D, Kinuthia W, Martin P, Mussen E C, Partap U, Taylor OR, Thomas GV, Thorp RW, Vergara CH, Winter K (2007). High quality bee products are important to agriculture: why, and what needs to be done, J. Apic. Res. 46 (1): 59-64

19. Krupke CH, Hunt GJ, Eitzer BD, Andino G, Given K (2012). Multiple routes of pesticide exposure for honey bees living near agricultural fields. 7:e29268.

20. Naccari C, Macaluso A, Giangrosso G, Naccari F, Ferrantelli $V$ (2014). Risk assessment of heavy metals and pesticides in honey from Sicily (Italy). J. Food Res. 3:107-117.

21. Nauen R, Ebbinghaus-Kintscher U, Salgado VL, Kaussmann $M$ (2003). Thiamethoxam is a neonicotinoid precursor converted to clothianidin in insects and plants. Pestic Biochem Physiol. 76:55-69.

22. Samson-Robert O, Labrie G, Chagnon M, Fournier V (2014). Neonicotinoid-contaminated puddles of water represent a risk of intoxication for honey bees. PLoS One. 9:e108443.

23. Sanchez-Bayo F, Goulson D, Pennacchio F, Nazzi F, Goka K, Desneux N (2016). Are bee diseases linked to pesticides? A brief review. Environ Int. 89:7-11.

24. Sanchez-Hernandez L, Hernandez-Dominguez D, Martin MT, Nozal MJ, Higes M, Bernal Yague JL (2016). Residues of neonicotinoids and their metabolites in honey and pollen from sunflower and maize seed dressing crops. $J$ Chromatogr A. 1428:220-227. 
25. Tapparo A, Marton D, Giorno C, Zanella A, Solda L, Marzaro M, Vivan L, Girolami, V (2012). Assessment of the environmental exposure of honeybees to particulate matter containing neonicotinoid insecticides coming from corn coated seeds. Environ. Sci. Technol. 46, 2592-2599

26. Tomizawa M, Casida JE (2005). Neonicotinoid insecticide toxicology: Mechanisms of Selective Action, Annu. Rev. Pharmacol. Toxicol., 45:247-68.

27. Vincent ML, Peters DG (1992). Electrolytic Cleavage of Acyclic and Cyclic Aromatic Esters. Case Studies of the Reductions of Benzyl Benzoate and Phthalide, J. Electroanal. Chem. 327 121-135.

28. Viuda-Martos M, Ruiz-Navajas Y, Fernández-López J, Pérez -Álvarez JA (2008). Functional properties of honey, propolis, and royal jelly. J. Food Sci., 73(9), 117-124

29. White JWJr (1957). The composition of honey. Bee World, 38(3), 57-66.

30. Williams GR, Troxler A, Retschnig G, Roth K, Yanez O, Shutler D, Neumann P, Gauthier L (2015). Neonicotinoid pesticides severely affect honey bee queens. Sci Rep. 5:18. 